1920
152

F. F. Hickman

Effect of Formalin on the viability of Pea Seeds 



\section{EFFECT OF FORMALIN \\ ON THE \\ VIABILITY OF PEA SEEDS}

BY

FERYL FRANCES HICKMAN

\section{THESIS}

FOR THE

DEGREE OF BACHELOR OF ARTS

IN

BOTANY

COLLEGE OF LIBERAL ARTS AND SCIENCES

UNIVERSITY OF ILLINOIS 



\section{0 \\ H52}

\section{UNIVERSITY OF ILLINOIS}

.........un.e..... $19: 20$.

THIS IS TO CERTIFY THAT THE THESIS PREPARED UNDER MY SUPERVISION BY Feryl Frances Hickman

ENTITLED ......ffect of Formalin on the Viability of P.g. Seeds

IS APPROVED BY ME AS FULFILLING THIS PART OF THE REQUIREMENTS FOR THE

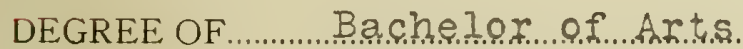

\section{Chas...F. Jottes}

APPROVED :

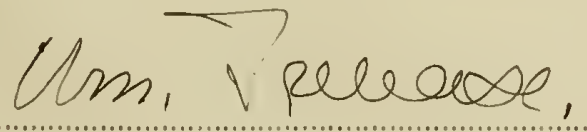

HEAD OF DEPARTMENT OF Botany. 



\section{TABLE OF CONTENTS}

Page

I. Introduction

1

II. Materials and Methods

5

III. Results and Discussion

6

IV. Conclusion 
Digitized by the Internet Archive in 2013 
TEE EFFECT OF FORMALIN ON THE VIABILITY

OF PEA SEEDS.

I. INTRODUCTION.

Formalin is extensivaly used for disinfection purposes. In treating seeds with formalin for the destruction of parasitic fung 1 it has been found to exercise an injurious effect upon the germination of seeds and later development of seedlings. The present rork was undertaken with the object of determining the effect of formalin treatment upon different varieties of peas.

In some instances the fungus is more resistant to the formalin treatment than the seed. In such cases some other than formalin treatment must be chosen. In every case it is well to know tho greatest concentration of solution that can be applied without undue injury to the seed.

R. de Zeeuw (1911) experimenting with different agents as potassium dichronate, mercuric chloride, hydrogen peroxide, formalin, etc., concluded that it is possible to obtain only an antiseptic effect.

From the various investigators using this agent there come diverse statements concerning its effectiveness as a fungicide and its injury to seeds and seedlings.

In the prevention of siats it has given different degrees of success. The dilutions used range from .02 to 2 per cent. The lower concentrations caused little injury to the seed while the higher resulted in injuries sufficient to require great caution in its use.

Young (1919) states that formalin is a generally successful agent and that fallure is usually due to lack of control on other factors. 

The conflicting statements concerning its effectiveness show that more information concerning its relations towards many kinds of seeds is needed.

Since the treatment with formalin must necessarily be done in aqueous solution, the absorption of the chemical through the normal imbibition processes of the seed enters as an important factor in determining the degree of injury. The degree of permeability or impermeability and the resistance of the seed coat or protoplasmic membrane to the agent control the degree of vitality of the seed in treatrent.

That there is a wide range in degree of permeability of the testa of different seeds is shown by the wori of Crocleer (1906), Brown (1907), (1909), and Shull (1913). Crocker founo that such coats may be extremely impermeable to gases and liquids. Brom (1909) discovered that some seed coats may have a selective permeability and resist the action for example of sulphuric acid.

Shull (1913) found semi-permeability to be of wide occurrence in seed coats. Fe found that cortain seeds can withstand, without injury, indefinite immersion in alcohol, ether and chloroform, providing the quantity of moisture present in the seed is very small. With some conpounds the degree of injury is determined by the quantity of water present, save for those solutions of extreme dilution.

Donny (1917) found that substances responsible for the impermeability could be dissolved and the character of the membrane destroyed. He also found that termeraturs increussd the permeability of the membrane. In studying the of fect of different agents on the same kind of seeds it was found that there are wide differancos in perneability and resistance exhibitad among variaties.

In peas accorilng to White (1917) this can be explainad by difierences in chemical composition, 1 . e., starchy or sugary peas. It was founz that seads with a larger sugar content and corpound small-sized starch grains have a greater capacity for absorption of water. The opposite is trus for the round, smooth 


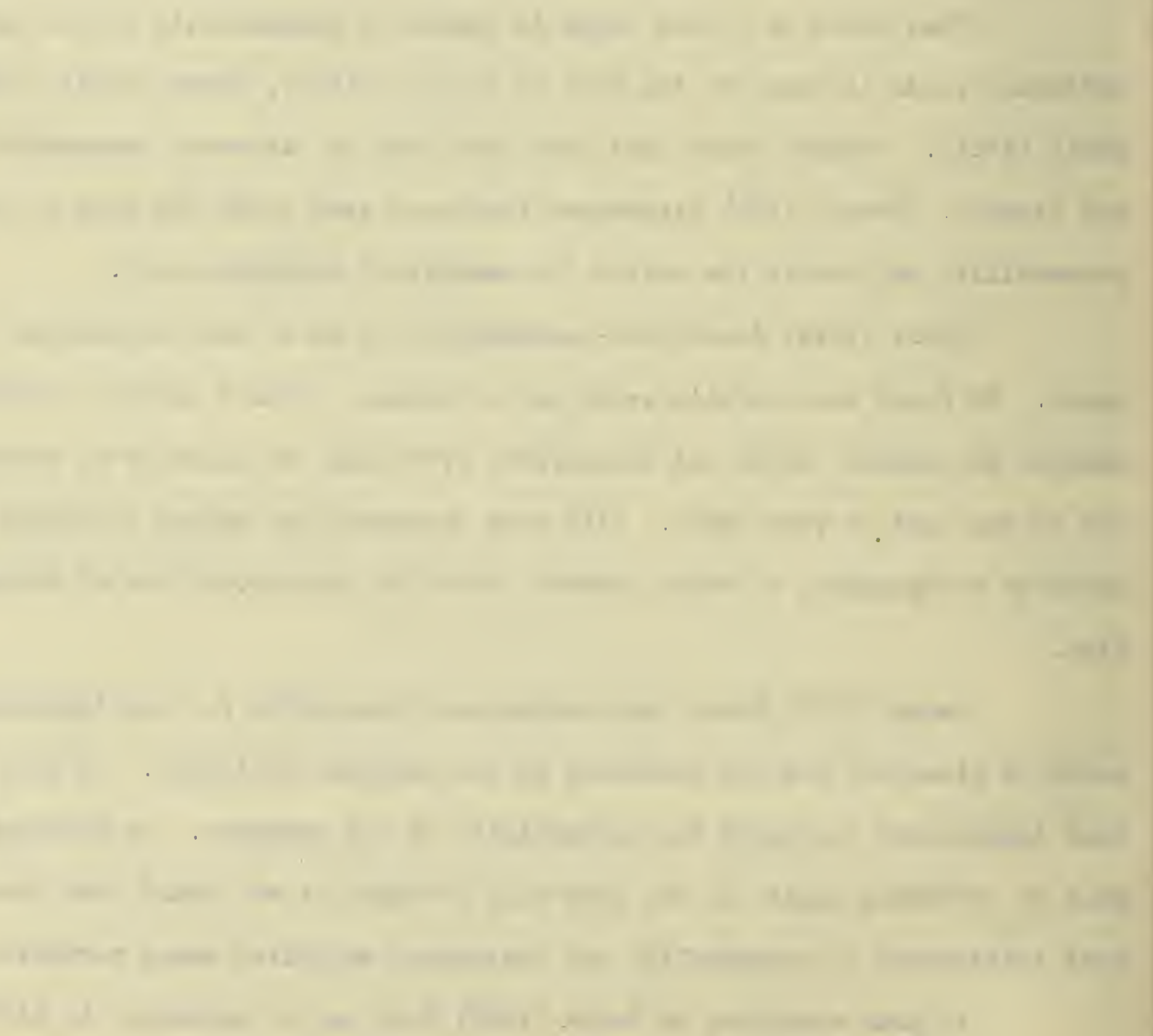

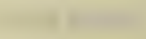


seads which have largo, simpls starch grains ani a smaller sugar content. Some of the latter seeds display greater impermeability of the coats and consequently have a greater resistance to the agont than have the pras with wrinkled coats and sugary content.

Miss Hind (1916) found that an increase in concentration decreased the time required to produce the toxic effect. Upon comparison of tine organic with the inorganic acids used she observed that the organic compounds had a decidedly more rapid effect upon permeability. She thought that this was perlaps due to the anion as well as the cation, and the fact that protoins have a great absorbing power and ease of reacting with acids.

The activity of formalin and its power to combine with proteids has been offered as an explanation of its poisonous qualities. Tho conflicting results obtained from different investigations have given rise to a question concerning its toxicity in different concentrations.

Arcichovskij (1913) in his experinents with different concentrations of poisonous substances upon peas expla1nod his results upon tise basis of loss ionization and greater polymerization in concontrated solutions. For the inorganic substances he suggests that they are due to the less relative and absoluto 10nization of concentrated as compared with that of the dilute solution. Although the proportion of ionized substances may be greater in the dilute, the numerical value for the concentration of the ions is less than the nurnerical value for the concentration of ions in the strong solutions. From this it would seen that the more concentrated solutions should be the most toxic. But this effect is greatly influenced by the perreability and rosistanco which tho seed has for tho particular compound or 1ons. The extent of these two qualities governs tho penetration of the solution.

With the non-eloctrolytic suistances he suggested that there was a greater polymerization in the concentrated solutions and so less activity. 

Bl1ss and Novy (1899) working with formalin found that the more concentrated solutions had a more toxic effect and that higher temperatures, as $40^{\circ} \mathrm{C}$, increased the poisonous effect.

Sherman (1905) states that "polymeric modifications of formalin in aqueous solutions closely resemble the original substarce in behavior to reagents".

On heating, the formalin that has polymerized breaks up to give formalin again. This is a characteristic for those substances which polyrerize.

The following exceriment was performed to determine the effect of formaIn upor the germination of different varieties of peas. Since different concentrations, as weak and strong often have unlike effects, or a similar effect but in different degrees, several concentrations were used. In order to observe the relation which time has to concentration different periods of soaleing were carried out. 



\section{MATERIALS AND METHODS.}

Four varieties of peas; Alaska, Canada Field, Black-eyed Marrowfat and Grajus were used. These verieties give a wide range in the degree of permeability of the coats as well as a rarked differonce in chemical composition, particularly with regard to sugar and starch content.

Formalin of varying concentrations closely following those of Arcichovskif's exporiment ware used. The actual soaking was carried on at a constant temperature of $35^{\circ} \mathrm{C}$. The seeds were selected to eliminate those with broken coats or other imperfections. Fifty weighed seed of each variety were placed in glass-stoppered bottles and together with the prepared solution subjectod for five hours to the constant tomperature of $35^{\circ} \mathrm{C}$. At the end of this period the solution was poured over the soeds. They remained in the formalin for tinirty, sixty or nirety minutes. At the end of each soaking the solution was pourei off, and the seeds thoroughly rinsed in tap water. They were then superficially dried bstween towels.

Since the time of immersion largely determines tine absorption of water and the chemical in solution the seeds were again weighed after treatment.

After weighing, the seeds were placed on plaster of paris blocks in germinating pans at $22^{\circ} \mathrm{C}$. for germination.

A period of eleven days was taken as the maximum to allow for germination. In a few cases whero seeds looked as if they had still tho power to germinate more time was given. In order to count a seed as germinated the tip of tho root or shoot had to be fres from the coat.

Each concentration was repeatad three times. At the end of each experiment the blocks and pans were carefully washed and ellowed to dry over night. 


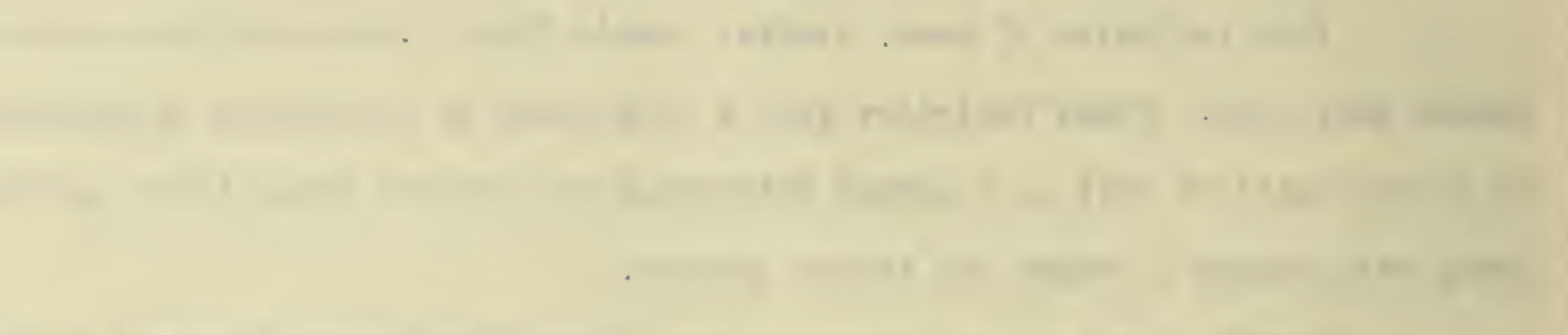

4in

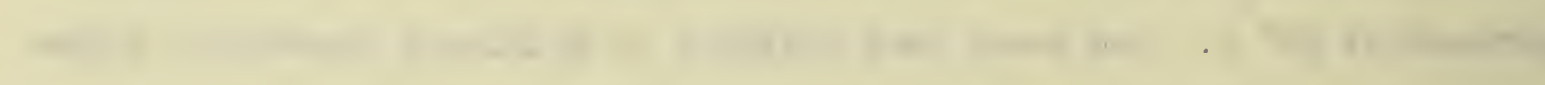

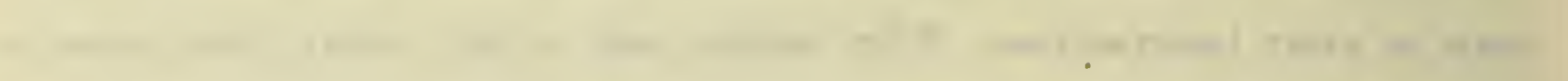

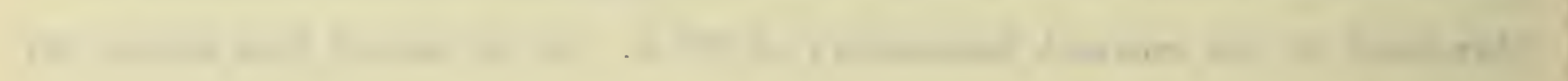

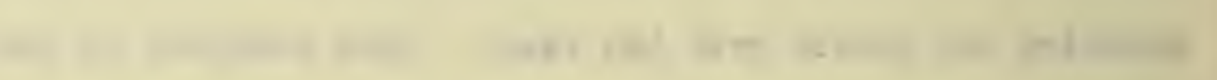

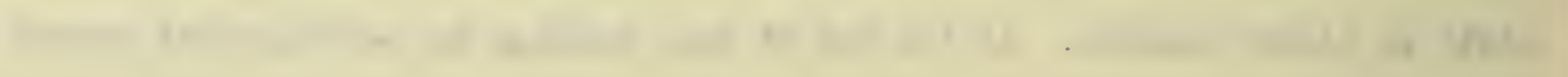
.

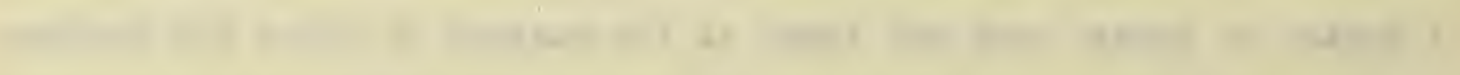

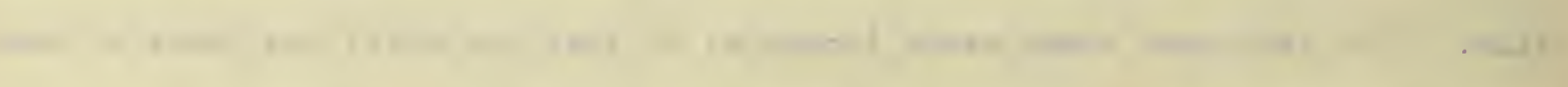

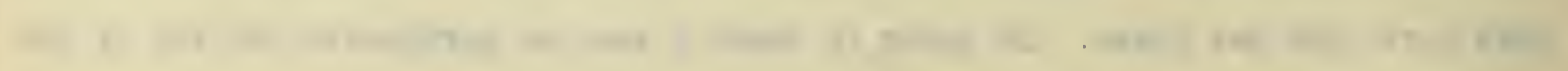
.

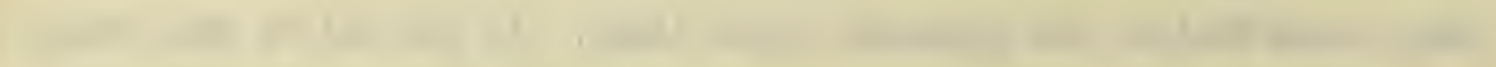

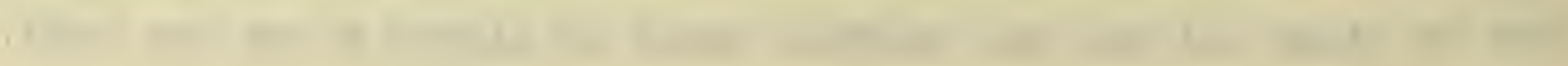


III. RESULTS AND DISCUSSION.

For the four varieties a general similarity of results was obtained. The graphs showing this are based on the averages of the three repetitions of each concentratinn, the numerical values of which are givon in tablas I, II, III and IV.

For the curves showing increase in weight there is a rise fron one per cent to 16 percent, at which point the greatest absorption occurs, rucceeded by a more or less Eradual decrease.

For Alaska, as shown by the curves in figurel, the rate of absorption in solutions of different concentrations, for periods of 30 and 60 minutes, shows a sharp decline to the 3 percent solution at which concentration there is a rapid rise. Seeds having a 90 minute immersion show this rise starting at 2 percent. This is perhaps due to a certain degree of impermeability and resistance which the seed coat of Alaske may have for formalin. In the longer periods of treatment as 90 minutes a sufficient time elapses to allow a dilvte solution to affect this partial impermeability. That there should be a drop at all may be explained by the bshavior of the water molecules in the imbibitional process. The seed coat with its varied degree of impermeability and resistance prevents the entrance of large quantities of the solute. The formalin may oppose to some extent the attraction of the seed coat for water and so result in a smaller increase in weight or a decrase in the rate of absorption.

The greatest absorption occurs in a 16 percent solution bacause the proportion between solute and solvent is most favorable. The decrease in weight gain for formalin ( 40 percent formaldehyde) and a $3 \hat{c}$ percent solution may be due in part 
. 
to an exosmosis during treatment as well as to the smaller anount of available water in the stronger concentrations.

There is a close correlation between the curves for gemination and the corresponding curves for rate and quantity of absorption. A slight increase in absorption shows a corresponding decrease on the germination curve, for instance the two curves between the concentrations 3 and 4 percent for seeds treated 30 and 60 minutes. (Fig. 1). The gemination for Alaska is greatly affected by increase in concentration until a lo percent solution is reashed; a 32 percent solution shows a decided rise which may be due to the decreased water content limiting the quantity of formalin and the depth of penetration and so the injury. The dror in germination which a 40 percent solution occasions is perhaps due to the increased amount of formalin ovarcoming the effect of a decreased water content.

Canada Field presents some differences. There is a smaller absorption of the solution in each of the concentrations, which is in keeping with its gmaller size and higher degree of impermeability of its coats for water in comcarigon with Alaska or Gradus. The impermeability or slow permeability of its costs for solutions of the higher concantrations acts as a protection and explains the greater toxicity of the dilute solutions, as 4 percent. The curves for Canada Field 11lustrate well that the smallar the absorption the less is the degree of injury. (Figure 2).

Of the four varities the coats of Gradus are the most permeable to water. As with Alaska the greatest absorption occurs in a 16 percent solution. (Figure 3). The curve for a 60 minute treatment exhibits a decline at 2 percent concentration and then a rise at 3 percent. For a 90 ninute immersion there is an abmpt rise to the 3 percent eolution followed by a decrease for 4 percent, from which point occurs a more gradual rise to 16 percent. The rate of absorption is not 


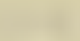

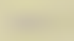

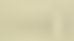
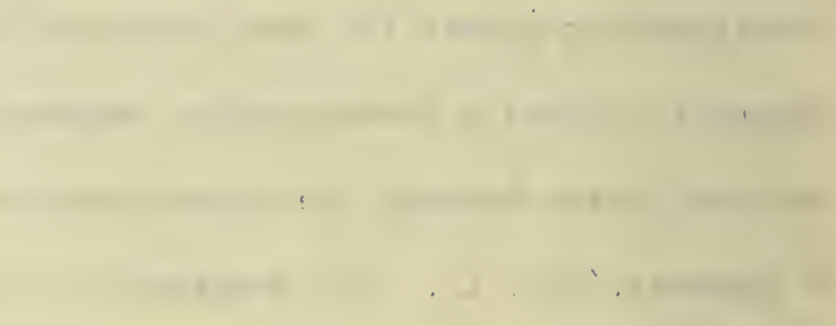

$+\cdot$ 
uniform for a whole period. This may account for the changes in weight for the concentrations from 1 to 4 percent. The curve (Figure 3) for a 60 minute immersion in a 2 percent solution shows the toxic action is still too weak to affect the permeability which offers a certain opposition to the absorption of the solution. With the increase to 3 percent an increased injury results and permits an increase in absorption over the 2 percent solution. The longer period of soaking brings out the differences that concentrations may show, particularly where dilute solutions are used.

Black-eyed Narrowfat was treated only with concentrations through 8 percent. There is a decrease in rate of absorption from 2 percent to 8 percent solutions which results from the decrease in water content and the limiting effect which time has upon concentrations. Tre curve for a 60 minute imrersion more clear ly shows this. (Figure 4).

Comparing the absorption curves for the four varieties the decrease for the high concentrations which Gradus and Canada Field present is caused by the diminished water content of the solution and in the case of Gradus an increased exosmosis during treatrent. This decrease is not evident for Alaska seeds soaked for 60 and 9C-minute periods as will be sean won comparison of the total absorption at 40 percent and 3 percent respectively. (Figure 1).

Canada Field because of the large number of imperneable coatg and differences in permeability of the successive randum samples shows a higher germination for seeds soaked 90 minutes than those for 60 minutes when a 40 percent solution was used. With this exception the lorger the period of soaking the greater is the degree of injuly to the seeds as shown by the percent of germination.

The relation between tizue and concentration is shown by the mimilar effects upon germination which a high concentration acting for a thirty minute feriod exerts as corparea with a low concentration for $6 C$ or 90 minute treatment. This is 

shown in Figure 1 where Alaska trasted for 30 minutes with formalin (40 percent formaldehyla) solution gives a result approximately equal to a 60 minute treatment with 4 percent.

The beliaf that the hich concentrations have a much smaller poisonous effect than weaker concentrations is not supported for formalin by these experiments.

The injury for the strongest solutions is approximately that for 2,3 and 4 percent solutions, the closeness depending upon the feriod of soaking. Both concentrations exert a marked injury. Even for a l percent solution there was a slight injury.

The occurrence and development of fungi as Rhizopus, Peniclilium and Asperglilus were not the same for all the varieties. The growth of fungi on treated peas results from the diffusicn from the seeds injured by the treatment. The growth of the mold was closely related to the degree of ahsorption of water and solute.

For the dilute solutions, 1 and 2 percent there was less mold and its occurrence was invariably upon those seeds which had highyy pemeabie or broken costs.

Canaia Fisld had very little mold until a 4 percent solution was used. From this concentration on there was alway a fairly evident development of white mold by the third day. Four or five days had been required in the wegker solutions for a fairly evident growth. The white mold developed best where there was seemingly a slight or moderate diffusion of organic materials from the seed.

Similarly the variety Alaska had only a slight development of fungi for concentrations 1 and 2 percent. With a 3 percent solution seeds treated for 90 minutes sometimes had no mola. When 4 and 8 percent solutions were used the arount of Penicillium and Aspergillus was increased while that of Rhizopts was 

inhibited.

With the use of higher concentrations the exosmosis was more pronounced and the quantity of formalin retained by the seed tissues probably much increased. This may account for the slight growth of Penicillium on seeds treated 60 and 90 minutes. Treatment with a 40 percent solution resulted in a decreased germination and comparatively little mold.

Gradus showed similar conditions for the dilute solutions 1 and 2 percent Seeds treated with 8 percent formalin for 30 and 60 minutes showed ir. some inseances white wold well started within four or five days. But those treated for 90 minutes were free from Rhizopus. Penicillium devoloped in some cases after five or six days, though usually there was no growth. For 16 and 32 percent solvtions Gradus showed the largest amount of ezomosis of the four varieties. The seeds immersed 60 or of minutes were most affected and had little or no mold development.

Mold occurred upon the checks but never to the extent that it did upon treated seeds. There was only very slight development of Penicilluim and Aspergillus upon the checks; the most common and abundant fungus were species of Rhizopis.

The vigor of germination was markedly affected by all concentrations above 2 percent.

The seeds subjected to a 30 minute inuersion in a 1 percent solution digplaved a vigorous grovth, but with longer periods of treatment injury became apparent. Scne seeds, wher 2 and 3 percent solutions were used, made a fair growth blit many exhibited a very weak germination and usually soon died.

of the four varieties Canada Field suffered the most. With higher concentrations its root just broke the coat, coiling up beneath. 



\section{CONCLUSION}

From a consideration of the results presented, formalin in solutions as dilute as one percent exerts an injurious effect, as shown by decreased germination, and a decreased vigor of seedling growth.

The poisonous effect of the higher concentrations was greater than that of the dilute for a thirty minute period of soaking in the case of Alaska and Gradus.

Longer periods of sosking tend in the case of Alaska and Gradus to give equal degrees of toxicity for high and low concentrations.

The smaller degree of injury upon Canada Field resulte from the nature of itg coats which have a higher degree of impermeabllity to water.

The greatest injury is caused by solutions of medium concentrations. 


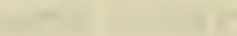

-

$\left(\frac{10}{20}\right.$

(n)

(20)

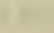

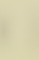

(-1)

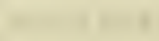

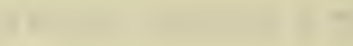

$-$

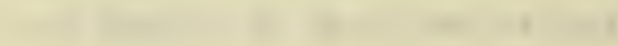

(2)

(2)

(1)

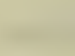

(1)

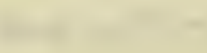

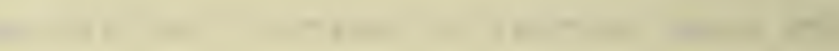


Table I. Alaska.

Lergth of

Treatment

Concentrations.

$\begin{array}{llllllll}1 & 2 & 3 & 4 & 8 & 16 & 32 & 40\end{array}$

Percent weight $\begin{array}{lllllllll}\text { increase } & 13 & 12 & 9 & 16 & 25 & 29 & 28 & 24\end{array}$

30 Minutes

Percent

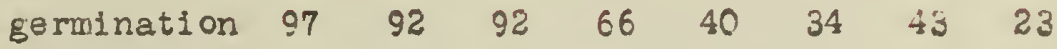

Percent weight

$\begin{array}{lllllllll}\text { ircrease } & 33 & 30 & 25 & 34 & 41 & 42 & 36 & 31\end{array}$

60 Minutes

Percent

$\begin{array}{lllllllll}\text { germination } & 85 & 61 & 55 & 19 & 13 & 2 & 23 & 13\end{array}$

Percent weight

$\begin{array}{lllllllll}\text { increase } & 47 & 42 & 43 & 47 & 49 & 57 & 45 & 36\end{array}$

90 Minutes

Percent

germination $\begin{array}{lllllllll}51 & 17 & 4 & 4 & 2 / 3 & 2 / 3 & 11 & 7\end{array}$

Check, percent germination

$99 \quad \begin{array}{lllllll}900 & 99 & 99 & 100 & 100 & 99 & 99\end{array}$ 



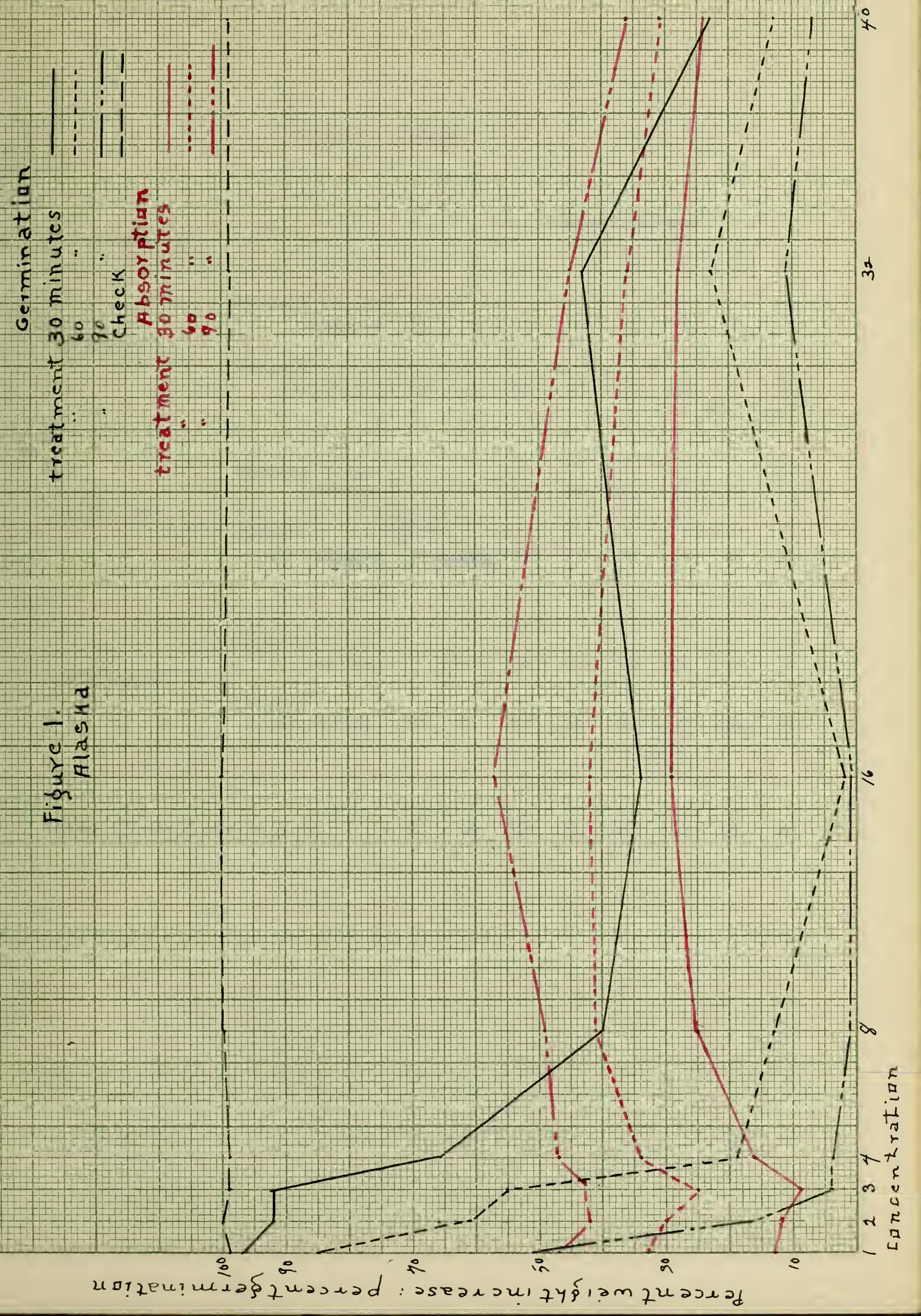



Table II. Canada

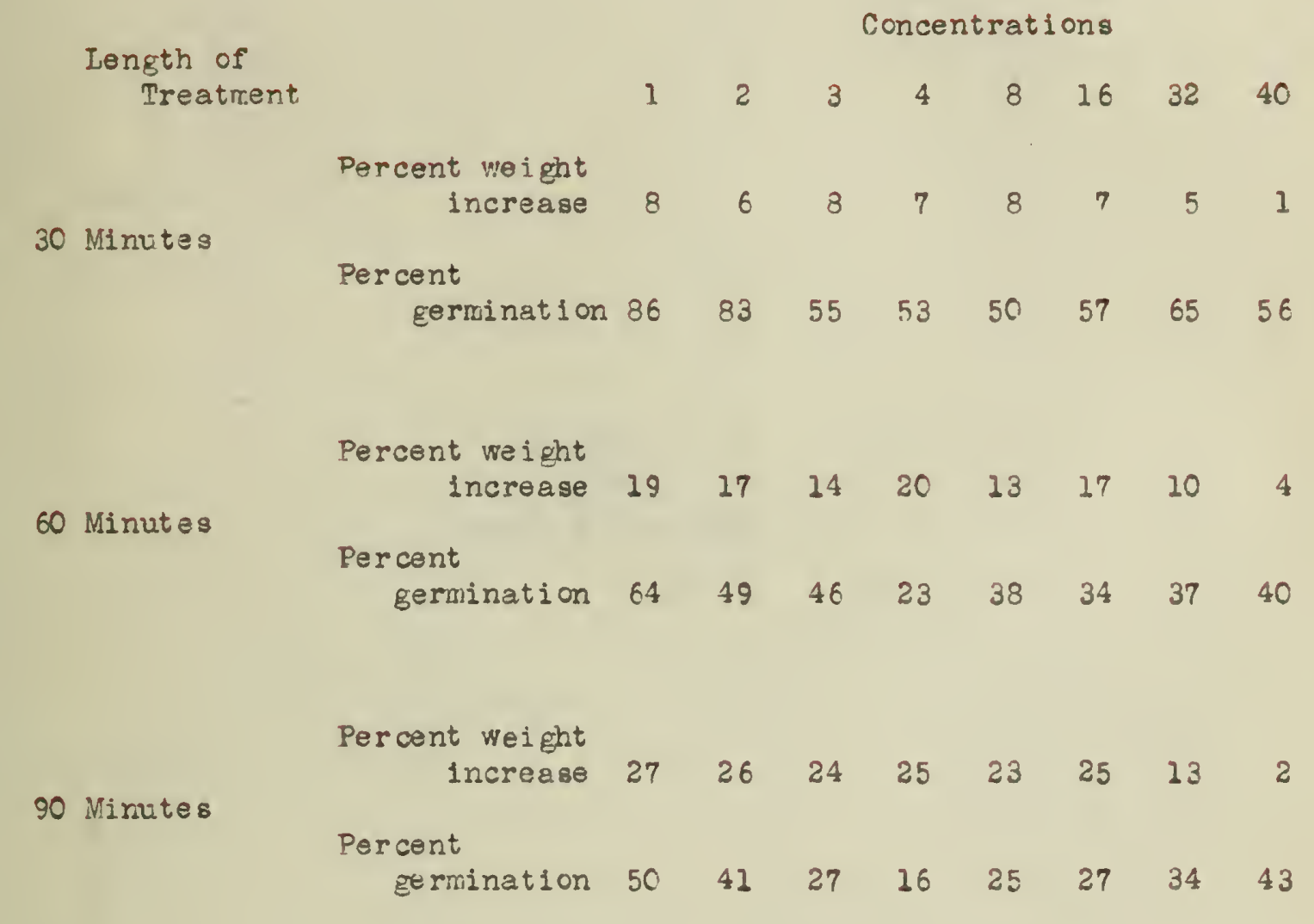

Check, peroent germination

$\begin{array}{llllllll}92 & 95 & 92 & 91 & 91 & 91 & 85 & 93\end{array}$ 



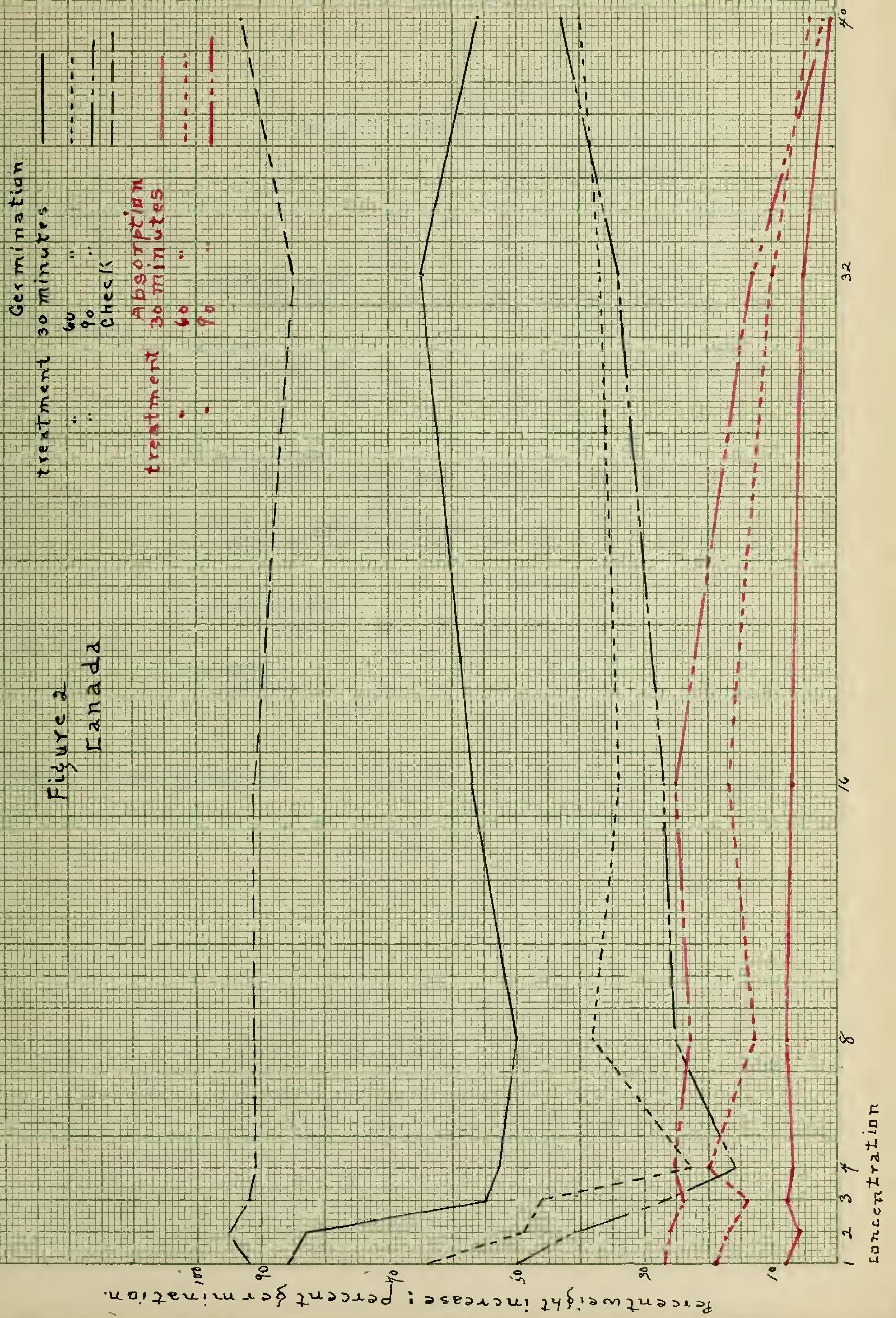



Table III. Gradus.

Concentrations

Length of

Treatment

Percent weight

increase

30 Minutes

Percent

germination

75

1

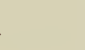

$33 \quad 34$

33

$38 \quad 41$

3120

Percent weight

increase

60 Minutes

Percent

germination

$52 \quad 45$

55

450

48

$\begin{array}{lll}53 & 37 \quad 19\end{array}$

55

$37 \quad 17$

$17 \quad 10$

Percent weight

increase

io Minutes

\section{Percent}

gernination

$\begin{array}{lll}55 & 58 & 61\end{array}$

54

61

64

$42 \quad 21$

$51 \quad 15$

5

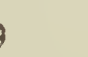

3

4

$2 \quad 5 \quad 16$

Check, percent germination

$\begin{array}{llllllll}93 & 98 & 91 & 83 & 83 & 87 & 91 & 83\end{array}$ 

$\mid \begin{array}{ccc}1 & 1 \\ \vdots & 1 \\ 1 & 1 & \vdots \\ 1 & 1\end{array}$

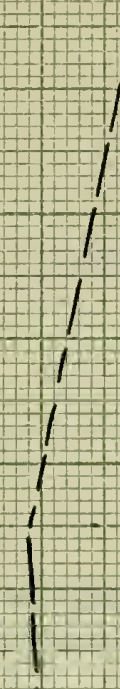

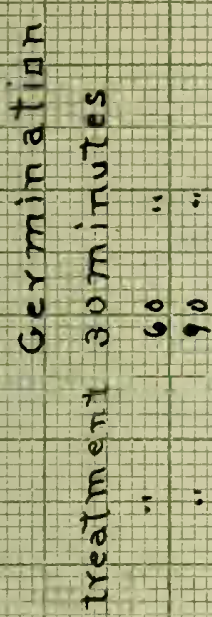

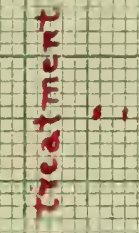

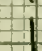

3
5
0
0
00
3
-0
4

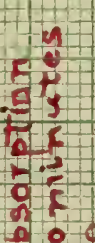

$\frac{0}{9} 90$ 

Table IV. Black-eyed Marrowfat.

\begin{tabular}{|c|c|c|c|c|c|c|c|}
\hline \multirow{2}{*}{\multicolumn{3}{|c|}{$\begin{array}{l}\text { Length of } \\
\text { Treatment }\end{array}$}} & \\
\hline & & & 1 & 2 & 3 & 4 & 8 \\
\hline \multirow{4}{*}{30} & & Percent weight & 17 & 38 & 15 & 74 & 74 \\
\hline & Minutes & & & & & & \\
\hline & & Percent & & & & & \\
\hline & & germination & 64 & 48 & 39 & 28 & 26 \\
\hline \multirow{4}{*}{60} & & Percent weight & & & & & \\
\hline & & increase & 34 & 34 & 31 & 30 & 26 \\
\hline & WInLles & Percent & & & & & \\
\hline & & gerxination & 36 & 21 & 19 & 9 & 15 \\
\hline \multirow{4}{*}{90} & & Per ant weight & & & & & \\
\hline & & increase & 42 & 43 & 42 & 41 & 43 \\
\hline & & Percent & & & & & \\
\hline & 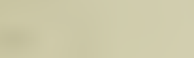 & germination & 21 & 8 & 7 & 2 & 7 \\
\hline Chech & ok, percen & at germination & 94 & 96 & 81 & 76 & 76 \\
\hline
\end{tabular}





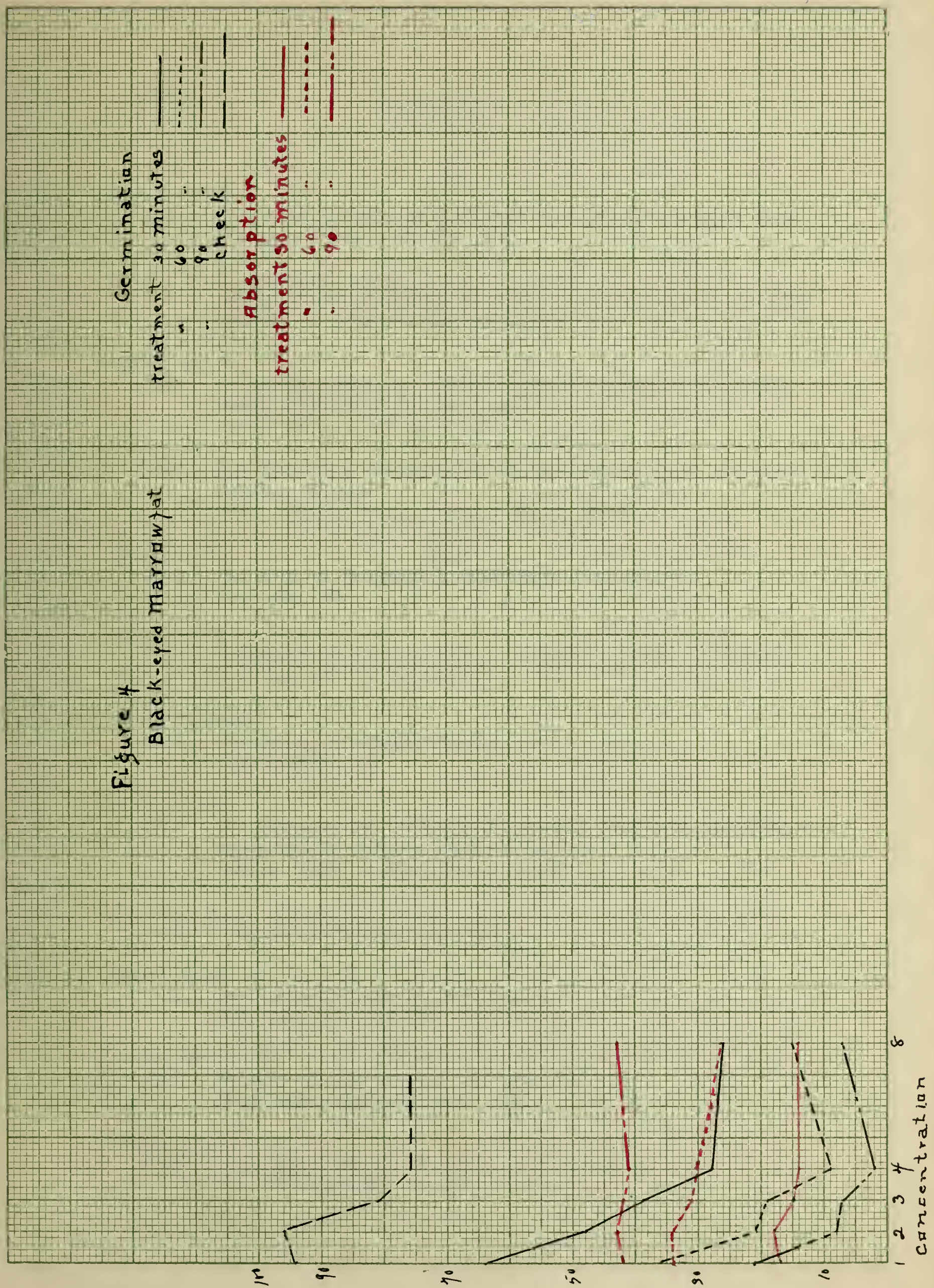

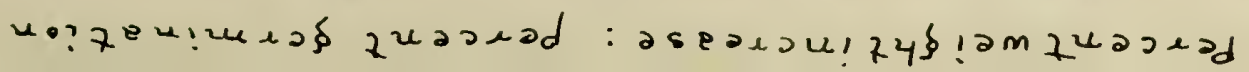



BIEI IOGRAPUY.

Arcichorskij

1913 Effect of poisong at different concentrations upon seeds. Bicchem. 2t schr. 50 ; No. 3-4.

Bliss, C. L. and Novy, F. G.

1899 Action of Formaldehyde on Enzymes and on Certain Proteids. Journal of Experimental Medicine. Vol. IV.

Brown, A. J.

1907 On the Existence of 2 Semi-permeable Merbrane enclosing the Seeds of some of the Graminae.

Annals of Bot. 21: p. 79-84.

1909 The Selective Permeability of the Coverings of the seads of Hordeum vulgare.

Proc. of Hoy. Soc., Lond. B 81: p. 82-93.

Crocker, W.

1906 The Role of Seed Coats in Delayed Germiration.

Bot. Gaz. 42.

Tenny, F. E.

1917 Permeability of Membranes as Related to Their Composition. Bot. Gaz. 63: p. $468-485$.

Hind, Mildred

1916 Studies in Permeability III.

Ann. of Bot. 30 .

R. de Zeeuw

1911 The Comparative viability of seeds, fungi and bacteria when subjected to various chemical agents.

Centbl. Bakt. 2 Abt; 3l: p. 4-2̌3.

Sherman, H. C.

1905 Methods of Organic Analysis.

Shull, Chas. A.

1913 Semi-permeability of Seed Coats.

Bot. Fidz. 56: 169-190.

White, O. E.

1017 Studies of Inheritance in Pisum II.

Proc. Amer. Philoso. Soc., 56.

Young, H. C.

1919 Seed disinfection for pure culture work.

Ann. Missouri Bot. Gardens, 6: April. 

$=$ 
